Supporting information for

\title{
From batch to continuous sustainable production of 3-methyl-3-penten-2-one for synthetic ketone fragrances
}

Xiaoda Wang, ${ }^{1}$ Peng Hong, ${ }^{1}$ Anton A. Kiss, ${ }^{2}$ Qinglian Wang, ${ }^{1}$ Ling $L i,{ }^{1 *}$

Hongxing Wang, ${ }^{3}$ Ting Qiu ${ }^{1^{*}}$

${ }^{1}$ Engineering Research Center of Reactive Distillation, Fujian Province

University, College of Chemical Engineering, Fuzhou University, Wulongjiang

Road, Fuzhou, 350108, Fujian, China.

2 Department of Chemical Engineering and Analytical Science, The University of Manchester, Sackville Street, Manchester, M13 9PL, United Kingdom.

${ }^{3}$ College of Chemical Engineering and Materials Science, Tianjin University of Science \& Technology, Thirteenth Street, Economic and Technological Development Zone, Tianjin 300457, Tianjin, China.

Corresponding authors: Prof. Ting Qiu, email: tingqiu@fzu.edu.cn;

Prof. Ling Li, email: liling@fzu.edu.cn

Pages: 4; Figures: 0; Tables: 0. 


\section{Details about TAC calculation}

TAC includes TCC and TOC. The TCC estimation follows the procedure of Douglas

[1]. To calculate TCC, the equipment size should be known.

\section{Equipment size}

\subsection{Condenser heat-transfer area $\left(A_{C}\right)$}

$A_{C}=\frac{Q_{C}}{U_{C} \times \Delta T_{C}}$

$Q_{C}(\mathrm{~kW})$ is the condenser heat duty. The overall heat-transfer coefficient $U_{C}$ is set as $0.852 \mathrm{~kW} / \mathrm{K} \cdot \mathrm{m}^{2} . \Delta T_{C}(\mathrm{~K})$ is the temperature difference in the condenser. The inlet and outlet temperatures of cooling water are set as $298 \mathrm{~K}$ and $308 \mathrm{~K}$, respectively.

\subsection{Reboiler heat-transfer area $\left(A_{R}\right)$}

$A_{R}=\frac{Q_{R}}{U_{R} \times \Delta T_{R}}$

$Q_{R}(\mathrm{~kW})$ is the reboiler heat duty. The overall heat-transfer coefficient $U_{R}$ is set as $0.568 \mathrm{~kW} / \mathrm{K} \cdot \mathrm{m}^{2} . \Delta T_{R}(\mathrm{~K})$ is the temperature difference in the reboiler, which is heated by water vapor.

\subsection{Column diameter $(D)$}

In this work, the column diameter is calculated by using the tray sizing tool in Aspen Plus.

\subsection{Column length $(L)$}

$L=0.609 N_{T}+3$ 
Total number of stage $N_{T}$ is necessary for the calculation of $L(\mathrm{~m}) .0 .609 \mathrm{~m}$ is the tray spacing, and 3 is the height for distributor et al.

\section{Equipment TCC (\$)}

All equipment materials are carbon steel. The TCC of each piece of equipment is calculated as follows.

\subsection{Column shell cost}

Shell cost $=\left(\frac{M \& S}{280}\right) \times\left(101.9 \times D^{1.066} \times L^{0.802}\right) \times\left(2.18+F_{C}\right)=15642.5 \times D^{1.066} \times L^{0.802}$

Marshall \& Swift index $(M \& S)$ of 1468.8 in 2019 is used in the calculation. $F_{C}=$ $F_{M} F_{P}$, where $F_{M}$ and $F_{P}$ are the equipment material and pressure coefficients, respectively. Since the carbon steel is chosen as equipment material, $F_{M}=1$. All the columns is operated at atmosphere pressure, so $F_{P}=1$.

\subsection{Column tray cost}

Tray cost $=\left(\frac{M \& S}{280}\right) \times\left(4.7 \times D^{1.55} \times L \times F_{C}\right)=510.2 \times D^{1.55} \times L$

$F_{C}=F_{S}+F_{T}+F_{M}$, where $F_{S}=1, F_{T}=0$, and $F_{M}=0$ are the tray spacing, tray type and equipment material coefficients, respectively.

\subsection{Heat exchanger cost}

$\mathrm{HX}$ cost $=\left(\frac{M \& S}{280}\right) \times\left(101.3\left(A_{R}^{0.65}+A_{C}^{0.65}\right)\right) \times\left(2.29+F_{C}\right)=9064.1 \times\left(A_{R}^{0.65}+A_{C}^{0.65}\right)$ $F_{C}=\left(F_{D}+F_{P}\right) F_{M}$, where reboiler type coefficient $F_{D}$ is 1.35 when the Kettle reboiler is used. $F_{M}=1$, and $F_{P}=0$.

\subsection{Reactor or tank cost}


Reactor cost $=\left(\frac{M \& S}{280}\right) \times\left(101.9 \times D^{1.066} \times L^{0.802}\right) \times\left(2.18+F_{C}\right)=15642.5 \times D^{1.066} \times L^{0.802}$ $F_{C}=F_{M} F_{P}$

\section{TOC (\$/year)}

TOC consists of steam cost, cooling water cost and electricity cost:

TOC $=\left(Q_{R} \cdot C_{S}+Q_{C} \cdot C_{C W}+Q_{E} \cdot C_{E}\right) \times 8000$

$Q_{R}$ and $Q_{C}$ represent the reboiler and condenser heat duties with the unit of $\mathrm{GJ} / \mathrm{h}$, respectively. The electricity consumption for the stirrer of BSTR is calculated by:

$Q_{E}=\frac{N_{P} \rho N_{i}^{3} D^{5}}{277.78}$

where, $N_{P}=0.35, \rho\left(\mathrm{kg} / \mathrm{m}^{3}\right)$ is liquid density, $N_{i}\left(\mathrm{~s}^{-1}\right)$ is the stirring speed, and coefficient 277.78 is to change the unit from $\mathrm{kw}$ to $\mathrm{GJ} / \mathrm{h}$. 8000 (h/year) is the annual working hour. The prices of heating stream, cooling water, and electricity $C_{S}, C_{C}$, and $C_{E}$ are listed as follows:

Low pressure stream $(433 \mathrm{~K})$ : $\$ 7.78$ per GJ;

Middle pressure stream (457 K): $\$ 8.22$ per GJ;

High pressure stream (527 K): \$9.88 per GJ;

Cool water $(298.15 \mathrm{~K})$ : $\$ 0.354$ per GJ;

Electricity: \$ 16.8 per GJ;

\section{REFERENCE}

[1] Douglas, JM. Conceptual Design of Chemical Process, New York: McGraw-Hill; 1988. 